\title{
Programa Mais Médicos e sua repercussão na mídia: o que informar e para quem?
}

\author{
Programa Mais Médicos and its repercussion in the media: what should \\ be informed and for whom?
}
Programa Mais Médicos y su repercusión en los medios de comunicación: qué y para quién informar?

Mateus Aparecido de Faria ${ }^{1, a}$

mateusfaria18@gmail.com | http://orcid.org/oooo-0001-6622-9949

Cristianne Maria Famer Rocha ${ }^{2, b}$

cristianne.rocha@ufrgs.br | https://orcid.org/oooo-0003-3281-2911

Liara Saldanha Brites ${ }^{2, c}$

liarabrites@yahoo.com.br | https://orcid.org/0000-0003-3474-0333

Angela Maria Grando Machado ${ }^{2, d}$

angel.grando@hotmail.com | https://orcid.org/0000-0001-7253-0092

Claiton Agnaldo Ribeiro Santos ${ }^{2, e}$

claitons68@gmail.com | https://orcid.org/oooo-0002-5469-4023

Neuza de Freitas Raupp Cechinel ${ }^{2, f}$

neuzaraupp@gmail.com | https://orcid.org/oooo-0003-1789-8358

Rossana dos Santos Rocha Mativi ${ }^{2, e}$

rossanamativi@gmail.com | https://orcid.org/0000-0002-4773-0604

\footnotetext{
${ }^{1}$ Fundação Oswaldo Cruz, Instituto René Rachou. Belo Horizonte, MG, Brasil.

${ }^{2}$ Universidade Federal do Rio Grande do Sul, Escola de Enfermagem. Porto Alegre, RS, Brasil.

a Graduação em Gestão de Serviços de Saúde pela Universidade Federal de Minas Gerais.

${ }^{\text {b }}$ Doutorado em Educação pela Universidade Federal do Rio Grande do Sul.

c Mestrado em Saúde Coletiva pela Universidade Federal do Rio Grande do Sul

d Graduação em Biblioteconomia pela Universidade Federal do Rio Grande do Sul.

e Graduando em Análise de Políticas e Sistemas de Saúde pela Universidade Federal do Rio Grande do Sul.

f Graduação em Saúde Coletiva pela Universidade Federal do Rio Grande do Sul.
} 


\title{
Resumo
}

O Programa Mais Médicos (PMM) foi instituído no Brasil no ano de 2013. Desde então, vem sendo debatida pela sociedade a questão de sua viabilidade, seus resultados e sua continuidade. O objetivo deste artigo é identificar e analisar a produtividade discursiva midiática, no período de maio de 2013 a julho de 2014, sobre o PMM. Foi feito um estudo exploratório e documental em uma revista semanal de grande circulação no Brasil (IstoÉ), através da busca de reportagens no seu sítio virtual, com descritores relacionados ao Programa, em que foram selecionadas 34 reportagens em 31 edições a partir do mês anterior à publicação da medida provisória que instituiu o PMM. A revista destacou a chegada de profissionais estrangeiros, os atos xenofóbicos empreendidos pela classe médica e a proteção corporativista da categoria. O PMM contribui grandemente para a melhoria da saúde da população e o atendimento de suas necessidades, porém reproduz a centralidade médica, desconsiderando que outros profissionais de saúde também têm sua atuação dificultada em áreas negligenciadas pelo Estado.

Palavras-chave: Programa Mais Médicos; IstoÉ; meios de comunicação; medicina comunitária; recursos humanos em saúde; saúde pública.

\begin{abstract}
The PMM - Programa Mais Médicos [More Doctors Program] was established in Brazil in 2013. Since it was announced, the question of its viability, results and continuity has been debated by the Brazilian society. The aim of this article is to identify and analyze the media discursive productivity in the first year (May 2013 to July 2014) of the PMM. An exploratory and documentary study of articles published in a weekly magazine of great circulation in Brazil (IstoÉ) was developed by means of a search for reports on its virtual site with descriptors related to the Program and 34 articles were selected in 31 editions from one month before the setting up of PMM by "medida provisória". The magazine noticed the arrival of foreign professionals, the xenophobic acts committed by Brazilian medical associations, and the category's corporative protection. The PMM contributes greatly to improve the health of the population and to satisfy its needs, but it reproduces the medical centrality, disregarding that the work of other health professionals have also been complicated in areas neglected by the State.
\end{abstract}

Keywords: Programa Mais Médicos; IstoÉ; mass media; community medicine; healthcare human resources; public health.

\section{Resumen}

El PMM - Programa Mais Médicos [Programa Más Médicos] se estableció en Brasil en 2013. Desde su origen, su viabilidad, resultados y continuidad han sido objeto de debate por la sociedad brasileña. Este artículo tiene el objetivo de identificar y analizar la productividad discursiva mediática, en el primer año (mayo de 2013 a junio de 2014) del PMM. Un estudio exploratorio y documental en una revista semanal de gran circulación en Brasil (IstoÉ) fue llevado a cabo, a través de la búsqueda de reportajes en su sitio virtual, con descriptores relacionados al Programa y se seleccionaron 34 reportajes en 31 ediciones a partir del mes anterior a la publicación de la "medida provisória" que ha establecido el PMM. El periódico destaca la llegada de profesionales extranjeros, los actos de xenofobia practicados por entidades médicas, y la protección corporativista de la categoría. El PMM contribuye en gran medida a mejora de la salud de la población y a atención médica de sus necesidades, pero reproduce la centralidad médica, sin tener en cuenta otros profesionales de la salud que también tienen su desempeño obstaculizado en áreas desatendidas por el Estado.

Palabras clave: Programa Mais Médicos; IstoÉ; medios de comunicación; medicina comunitaria; recursos humanos en salud; salud pública. 
Contribuição dos autores:

Concepção e desenho do estudo: Faria MA, Rocha CMF, Brites LS, Machado AMG, Santos CAR, Cechinel NRF e Mativi RSR. Aquisição, análise ou interpretação dos dados: Faria MA, Rocha CMF, Brites LS, Machado AMG, Santos CAR, Cechinel NRF e Mativi RSR. Redação do manuscrito: Faria MA, Rocha CMF, Brites LS, Machado AMG, Santos CAR, Cechinel NRF e Mativi RSR. Revisão crítica do conteúdo intelectual: Faria MA, Rocha CMF, Brites LS, Machado AMG, Santos CAR, Cechinel NRF e Mativi RSR.

Declaração de conflito de interesses: Não há conflito de interesses.

Fontes de financiamento: Não houve financiamento.

Considerações éticas: Por se tratar de dados secundários de acesso aberto, não foi necessário submeter ao Comitê de Ética. No entanto, as premissas da pesquisa ética foram respeitadas.

Agradecimentos/Contribuições adicionais: Agradecemos a Ariza MBA pelas importantes contribuições analíticas no campo da Comunicação Social.

Histórico do artigo: Submetido: 06.fev.2017 | Aceito: 28.nov.2017 | Publicado: 30.mar.2018.

Apresentação anterior: não houve.

Licença CC BY-NC atribuição não comercial. Com essa licença é permitido acessar, baixar (download), copiar, imprimir, compartilhar, reutilizar e distribuir os artigos, desde que para uso não comercial e com a citação da fonte, conferindo os devidos créditos de autoria e menção à Reciis. Nesses casos, nenhuma permissão é necessária por parte dos autores ou dos editores.

\section{O Programa Mais Médicos}

O Sistema Único de Saúde (SUS) está em grande destaque, por conta do seu objetivo universalizador, da sua organização descentralizada e da garantia constitucional de sua implantação ${ }^{1}$. Após mais de duas décadas sendo construído em arenas de disputas políticas, o SUS enfrenta atualmente o desafio de ampliar a Atenção Básica e, consequentemente, o seu quadro de trabalhadoras(es). A falta de médicos nas unidades de saúde se insere neste cenário, com bastante clamor público². A proporção de profissionais de medicina para a população brasileira é significativamente inferior à de países vizinhos: enquanto há 1,8 médicos para cada 1.00o habitantes no Brasil, existem 3,2 médicos/100o hab. na Argentina e 3,7 médicos/100o hab. no Uruguai. Estima-se que essa relação deveria ser de 2,7/100o hab. para que o SUS pudesse atender mais adequadamente as necessidades de saúde da população do país ${ }^{2}$. O desafio torna-se ainda maior quando esse dado é desagregado e percebe-se grandes disparidades entre as cinco regiões brasileiras.

A falta de médicos, visível principalmente nas comunidades remotas e vulneráveis, foi alertada em janeiro de 2013 pela campanha “Cadê o médico?”, realizada pela Frente Nacional de Prefeitos ${ }^{3}$. Em resposta aos prefeitos e aos gritos das ruas, que pediram mais saúde durante as manifestações de junho de 2013, no mês seguinte, foi instituído o Programa Mais Médicos para o Brasil (PMM) pelo Governo Federal ${ }^{4}$.

Com a intenção de um amplo pacto para a melhoria do atendimento aos usuários do SUS, o PMM tem como objetivos: levar médicos para locais afastados dos grandes centros urbanos, com vulnerabilidade socioeconômica ou onde exista carência desse tipo de profissional; investir na infraestrutura de Unidades Básicas de Saúde (UBS) e Unidades de Pronto Atendimento (UPA); e reestruturar e expandir a formação médica, em parceria com Ministério da Educação (MEC), com a abertura de novas vagas nos cursos de medicina e de especializações, voltadas para as demandas do SUS4.

A trajetória do PMM, desde a sua criação, divide opiniões, principalmente entre os profissionais médicos. Os conselhos de medicina divulgaram notas com críticas em relação ao Programa, como o fato dos estrangeiros atuarem sem a devida revalidação de diplomas ou a falta de transparência e de fiscalização 
do convênio firmado com a Organização Pan-Americana de Saúde ${ }^{5}$. No entanto, pesquisa divulgada pelo Governo Federal afirma que $83 \%$ dos usuários do SUS estão satisfeitos com o atendimento prestado e que $74 \%$ acreditam que o Programa está melhor do que o esperado 6 . Mais recentemente, outra pesquisa divulgou dados que corroboram essa percepção positiva do trabalho médico estrangeiro, revelando que mais de $90 \%$ dos usuários avaliaram como bom ou muito bom o atendimento e cerca de $72 \%$ avaliaram como bom ou muito bom a responsividade do serviço melhorado com o $\mathrm{PMM}^{7}$.

Apesar das críticas feitas pelas entidades médicas ao Programa, o número de profissionais médicos que o integram demonstra a magnitude do problema relacionado à falta de profissionais. Até dezembro de 2016, aproximadamente 18.240 profissionais integraram o PMM, distribuídos em 4.058 municípios, 34 distritos sanitários especiais indígenas (DSEIs), atendendo cerca de 134 milhões de pessoas. Além disso, foram criadas mais 5.306 vagas de graduação em medicina (32\% em instituições públicas), 4.472 vagas em residências médicas e 26 mil UBS foram construídas, ampliadas ou reformadas ${ }^{8}$.

Durante esse período, os meios de comunicação foram, possivelmente, os mais eloquentes na produção, transmissão e cobertura de pontos de vista que (re)produziam posições favoráveis ou contrárias em relação ao PMM.

Com a intenção de identificar e analisar a produtividade discursiva da mídia brasileira a respeito do Programa Mais Médicos em seu momento de gênese, escolhemos, neste artigo, uma das revistas brasileiras mais antigas e mais influentes no cenário nacional: a IstoÉ. Trata-se de uma revista semanal, de conteúdo generalizado, voltada para o público adulto, editada na cidade de São Paulo/SP. Alcança mais de meio milhão de leitores por mês, é a terceira mais vendida por semana ${ }^{9}$, além de ser considerada, segundo o sítio virtual da revista, como "a mais combativa revista semanal do País".

\section{Procedimentos metodológicos}

O presente estudo, de cunho exploratório-documental e de abordagem qualitativa e quantitativa, integra o projeto de pesquisa 'Saúde na mídia: análises sobre a produtividade discursiva na imprensa brasileira', de iniciativa da Universidade Federal do Rio Grande do Sul (UFRGS) em parceria com a Universidade Estadual do Rio Grande do Sul (UERGS).

Para coleta dos dados, foi utilizada a ferramenta de busca do sítio virtual da revista IstoÉ com os descritores 'Programa Mais Médicos para o Brasil', 'Projeto Mais Médicos' e 'Mais Médicos', no período de maio de 2013 a julho de 2014. Salvo junho de 2013, esse período corresponde justamente ao primeiro ano do PMM, focalizado pela revista estudada mesmo antes de iniciado. Foram então selecionadas 34 reportagens em 31 edições.

A análise de dados foi realizada a partir da análise de conteúdo na modalidade temática ${ }^{10}$, seguindo as etapas de pré-análise, exploração do material, tratamento dos resultados e interpretação. Iniciou-se a análise com leitura flutuante das reportagens previamente selecionadas. A partir dessa primeira leitura, foi elaborada uma planilha de análise para destacar os elementos mais importantes de cada reportagem, que nos permitissem, na sequência, analisar o que é dito, como é dito, por quem são proferidos os discursos a respeito do PMM, entre outros aspectos. A planilha contemplou informações sobre cada uma das reportagens: referência completa (título, autoria, data de publicação, página), temas principais abordados, personagens, argumentos utilizados ou discursos proferidos, autores e tendenciosidade (se positiva, negativa ou neutra). A construção da planilha baseou-se em trabalhos anteriores ${ }^{11,12}$, ambos com métodos e objetivos semelhantes aos desta pesquisa.

Para cada reportagem, uma dupla de pesquisadores preencheu a planilha. No final, os dados coletados a respeito de cada reportagem foram colocados em uma única planilha, de tal forma que as divergências fossem evidenciadas: quando existia alguma acerca de algum aspecto, um terceiro pesquisador buscava esclarecer o conflito. 


\section{Resultados e discussão}

Das 34 reportagens selecionadas na revista IstoÉ, a maior parte delas - $19(55,9 \%)$ - foi publicada no ano de 2013 (de junho a dezembro). As 15 restantes, correspondentes a 44,1\%, foram publicadas nos seis meses subsequentes (de janeiro a junho de 2014). O maior número absoluto de reportagens ainda no ano de 2013 parece demonstrar que a revista investiu em trazer ao público leitor a polêmica aprovação do PMM, em função da contratação de médicos estrangeiros e da "criação de um período obrigatório de dois anos de serviço no SUS como parte dos cursos de medicina em instituições públicas e privadas" ${ }^{13}$, que mobilizou a classe médica no país, através de suas entidades.

Não só muitos médicos se manifestaram contrariamente à implementação do Programa, mas também ocorreu forte oposição de alguns partidos políticos. O senador Cyro Miranda (PSDB-GO) classificou o PMM como "populista, obra de marketing e jogada eleitoreira"14 e o senador José Agripino (DEM-RN) disse, em plenária, que "o governo não ouviu o povo [pois...] não soube tomar providências eficazes para responder às demandas da sociedade que se mobilizou e foi às ruas há mais de um mês para exigir melhorias por parte dos dirigentes do país" ${ }^{15}$.

Quanto aos principais personagens mencionados nas reportagens, os médicos estrangeiros/cubanos foram os mais presentes (em 12 reportagens), seguidos da presidenta Dilma Rousseff (citada em 10), do então ministro da saúde (Alexandre Padilha) e dos médicos brasileiros (ambos citados em sete).

Em relação à tendência das reportagens, consideramos como positivas aquelas que enalteciam/ elogiavam a implementação do Programa, como negativas as que continham a crítica como tônica central da reportagem e como neutras as informativas sem muitos adjetivos. Do total das 34 reportagens selecionadas, a maior parte delas teve um cunho positivo (16) ou neutro (11).

Em relação às temáticas tratadas, o cunho político da criação e implementação do Programa, seja pela mobilização inicial do governo, seja pela crítica da oposição, é apresentado ao leitor. No período entre janeiro e junho de 2014, houve a consolidação do PMM e uma melhor aceitação por parte da sociedade e dos usuários do SUS. Nesse período, o Programa passou a ter uma visibilidade positiva, em um cenário pré-eleitoral. Tal fato gerou críticas e a IstoÉ chegou a citar uma nota do Conselho Federal de Medicina que considera o PMM uma decisão "eleitoreira" e que "coloca em risco a saúde da população"16, e em algumas reportagens associou o Programa e a postura imprópria das entidades médicas às melhorias dos índices de popularidade da presidente Dilma.

O ministro da saúde, Alexandre Padilha, atribuiu aos prefeitos a ideia original de contratação de profissionais de outros países para atuarem no SUS: "Aliás quem começou essa história de médicos estrangeiros foram os prefeitos"17. Em reportagem posterior, o governador de Pernambuco e candidato presidencial, Eduardo Campos, atribuiu um marketing político ao PMM em vez de clamor dos entes federativos: "Mais Médicos não pode ser Mais Marketing"18.

A revista traz os questionamentos das entidades médicas a respeito do Programa, mas também apresenta argumentos a respeito da situação sociossanitária brasileira: "não faltam médicos, falta estrutura mínima para que eles trabalhem na rede pública, diz o Presidente do CFM"13. E também publica críticas ao posicionamento dos profissionais médicos e suas representações, considerado como reação "corporativa, xenofóbica e racista", por "proteção de mercado de trabalho"19 diante da "quebra de um monopólio"16. 
Em uma reportagem intitulada "Doentes de Ideologia" ${ }^{20}$, a revista mostra como esses profissionais médicos reagem com "fúria e preconceito" ${ }^{20}$ ao Programa e à iniciativa federal de trazer os médicos estrangeiros, particularmente os cubanos ${ }^{20}$, que desembarcavam no País "para trabalhar em locais onde os médicos brasileiros se recusam a residir” ${ }^{21}$.

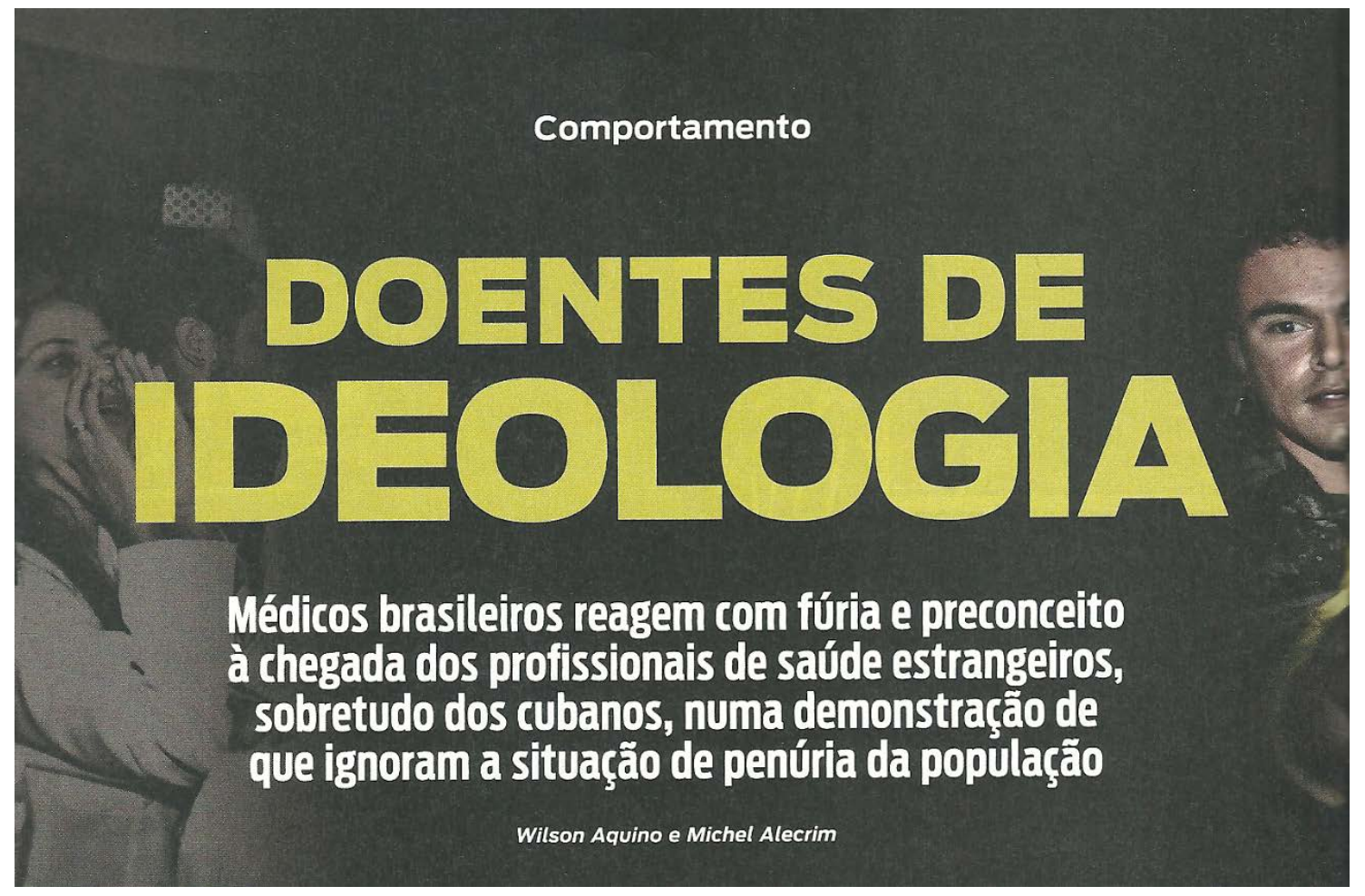

Figura 1. Doentes de ideologia

Fonte: Aquino e Alecrim (2013) ${ }^{20}$

Apesar de o PMM ter mais de uma estratégia de intervenção na situação médica no país (como investimento em infraestrutura e reestruturação e expansão da formação profissional) e, durante o período pesquisado, já haver médicos brasileiros no Programa, um dos temas bastante evocados pela IstoÉ nas reportagens sobre ele é a falta desses últimos e a importação de estrangeiros (principalmente cubanos).

É apresentada ao leitor a dificuldade de quem não consegue contratar profissionais médicos, como o gestor de um hospital que refere estar "mais fácil achar ouro do que médico" ${ }_{13}$. Tal percepção é reforçada pelo ministro da saúde Alexandre Padilha: "Temos uma média de 1,9 médicos por mil habitantes. Esta cifra está abaixo de toda a América Latina e distante da média de países europeus, como Inglaterra, Espanha e Portugal" ${ }^{17}$. E, na mesma matéria, também é apresentado o contraponto: "Os quatro estados da região Sudeste concentram 38\% das Unidades Básicas de Saúde, dos hospitais gerais e dos hospitais especializados. Daí terem $56 \%$ dos médicos brasileiros. A informação é a nova arma do Conselho Federal de Medicina para tentar impedir a entrada no Brasil de 'médicos do Exterior'. O Ministério da Saúde não dá ouvidos às reclamações”"17.

Em geral, a falta de médicos é trazida na IstoÉ como questão de "saúde pública"22; por isso, trazer médicos estrangeiros é visto como "ponto forte do programa" e como "decisão política drástica" ${ }^{13}$.

Essa falta dos profissionais e a necessidade deles nas áreas vulneráveis também são marcantes nas imagens. Em reportagem especial, no princípio do PMM, o texto de capa já destaca que "a carência de atendimento nas regiões mais isoladas do país e nas periferias das grandes cidades exige uma solução urgente. O plano de trazer médicos do exterior, que o governo anuncia nesta semana, pode ser uma revolução se resolver o problema de multidões que vivem à margem do sistema de saúde"13. 
Na imagem, em preto e branco, o rosto de uma criança negra com olhos observadores, protegida pelo corpo de um adulto negro, retratam a realidade brasileira, em que a maioria da população de menor renda é negra:

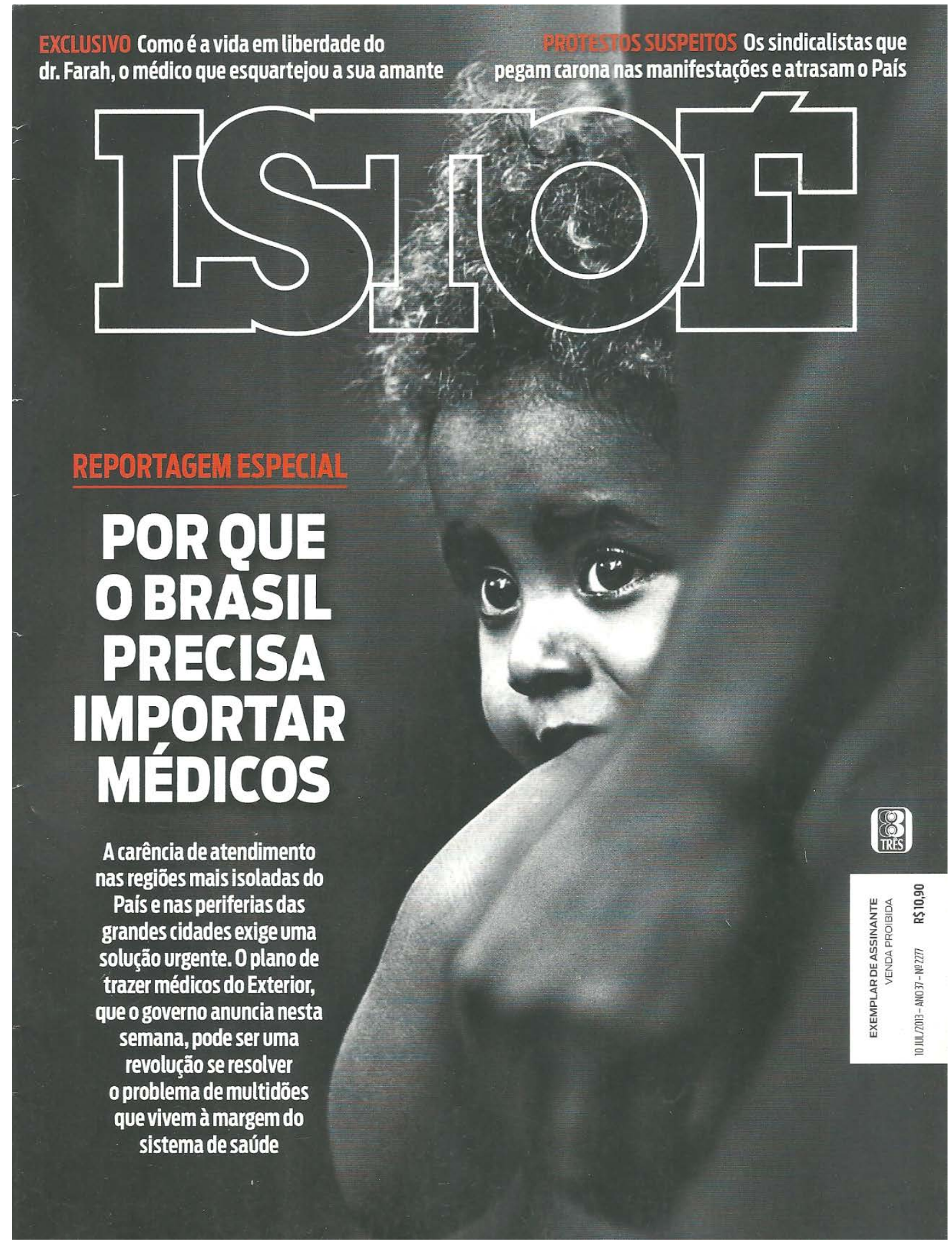

Figura 2. Por que Brasil precisa importar médicos Fonte: Leite e Torres (2013) ${ }^{13}$ 
Ainda na mesma reportagem de capa, em preto e branco, o grifo no título enfatiza que o Brasil precisa de médicos e o cenário é um hospital aparentemente superlotado de pacientes:

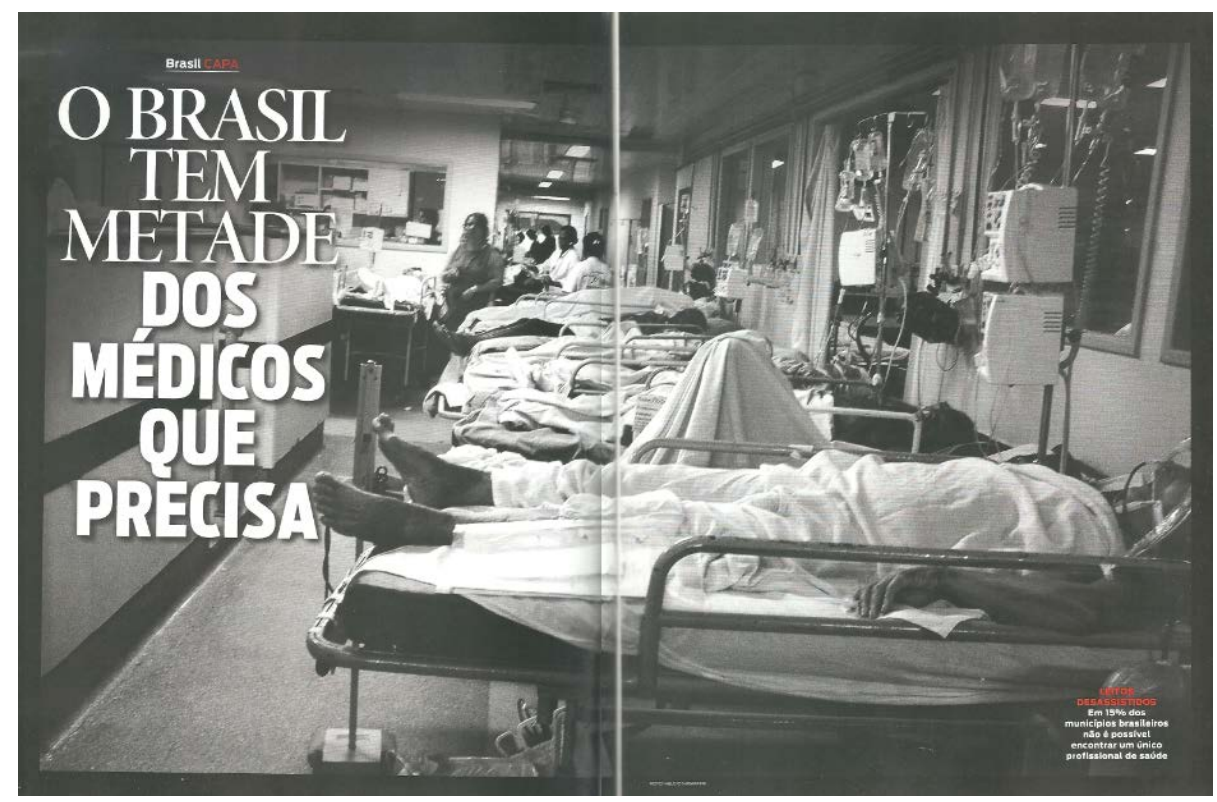

Figura 3. O Brasil tem metade dos médicos que precisa Fonte: Leite e Torres (2013) ${ }^{13}$

O "retrato dramático da saúde pública no Brasil"13, ainda em preto e branco, é o pátio de uma casa construída com tapumes, com pessoas negras e uma médica branca atendendo, de tênis:

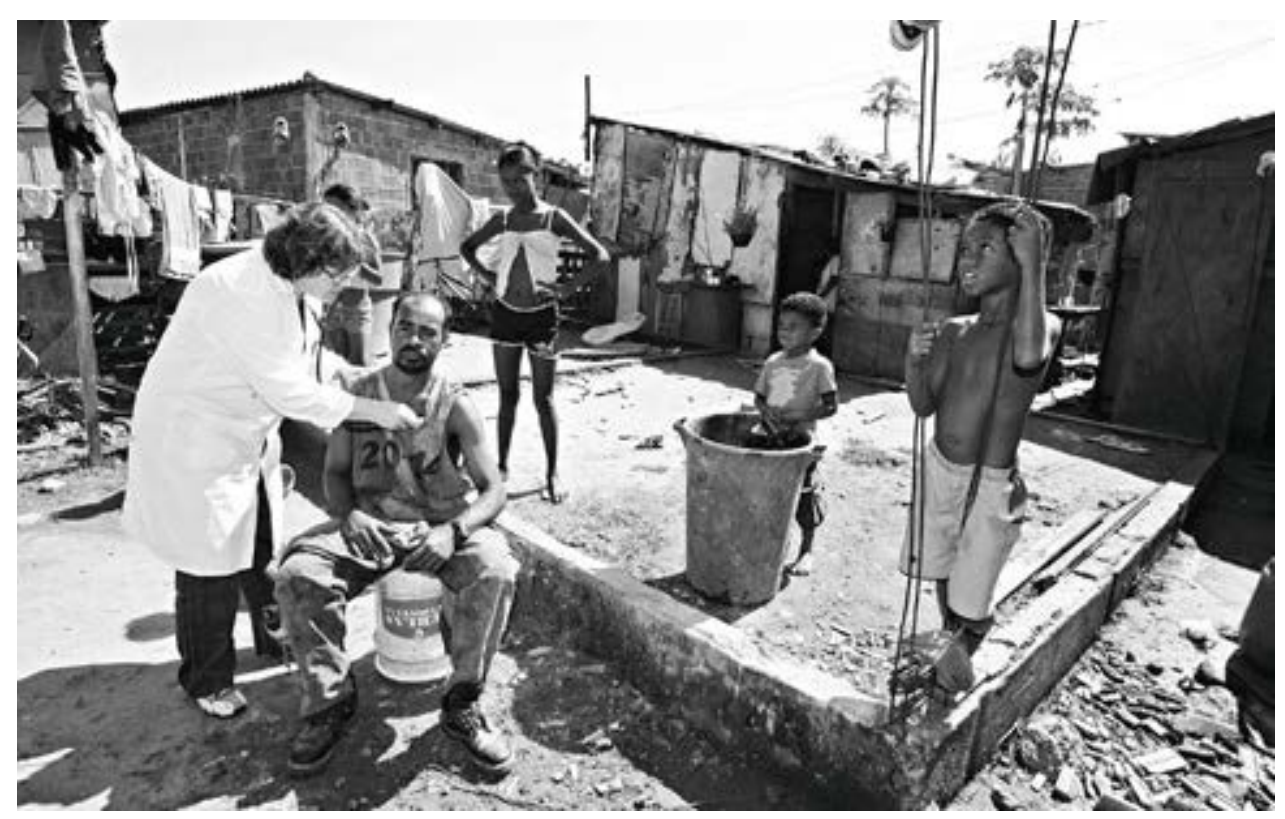

Figura 4. Conheça o retrato dramático da saúde pública no Brasil e saiba por que o programa do governo de importação de médicos pode ajudar a resolver esse flagelo

Fonte: Leite e Torres (2013) $)^{13}$

Os resultados mostram o PMM reconstruído como notícia, processo que envolve tanto fatores intrínsecos ao evento, como caminho para aprovação legislativa, e o número de médicos estrangeiros contratados para atuação em áreas prioritárias, como fatores extrínsecos, que envolvem organização jornalística da IstoÉ, social e cultural ${ }^{23}$. Os fatores intrínsecos, ou também chamados de valores-notícia, são os que chegam mais 
nitidamente ao público almejado, perceptíveis pelo uso e escolha do léxico de cada notícia, indicando quais valores ela quer acionar nos mapas de significados dos leitores. Esse mapa ou esquema são representações compartilhadas socialmente, em que se inserem preocupações, interesses e afetos. Quando a IstoÉ define quais mapas serão focalizados em sua publicação semanal, ela opera uma seleção do que vai ser noticiado e, consequentemente, uma construção do que foi selecionado ${ }^{23}$, já que há diferenças entre fato vivido, fato narrado e fato compreendido.

Os fatores extrínsecos atuam na noticiabilidade do PMM por conta, como exemplo, da periodicidade da IstoÉ, pois sendo semanal é preciso elaborar estratégias de manter-se atual e comprável em tempos de spot news ${ }^{24}$. Isso auxilia o entendimento das intenções de publicizar títulos como o presente na Figura 5 - mesmo com equívocos conceituais ("medicina básica”), esse enunciado evoca intertextualidades que buscam chamar a atenção do consumidor-leitor.

A mediação entre esses dois fatores é feita pelo profissional jornalista que possui mapas de significados muito particulares, usados para ver certos eventos e não outros, e vê-los de determinada maneira e não de outra ${ }^{23}$. Tais decisões são ancoradas na legitimação de espaços e tempos: o PMM aparece no tempo das manifestações de junho de 2013 e em espaços democráticos de intensas disputas. Há de se considerar também que, no cotidiano do trabalho do jornalismo, a editoração do veículo comunicacional exerce forte influência na definição do que vai ser escrito e como vai ser feito. Estabelecem-se, então, por vezes, conflitos entre os mapas de significados individuais dos jornalistas e decisões do editor chefe, que podem, inclusive, não condizer com seus próprios mapas, já que existem pressões de outra ordem nesse processo. Na análise das matérias não foi possível analisar essa disputa de forças, pois seriam necessárias estratégias metodológicas mais próximas da observação participante ${ }^{23}$.

No entanto, a mediação não se encerra na equipe editorial da IstoÉ; ela leva em consideração também os esquemas de relevância dos receptores ${ }^{24}$. O que é importante para quem compra a revista? O que precisa estar na capa para que os consumidores-leitores a considerem relevante o suficiente para comprá-la? As notícias do PMM abriram espaço muito reduzido para as opiniões da parcela da população atendida, comparativamente com as de outros atores, o que nos leva a refletir se essas vozes não são relevantes (para a IstoÉ, para os receptores ou para ambos) ao construir a matéria sobre o fato.

Outro ponto necessário à discussão são as imagens escolhidas para materializar os sentidos da expressão $0^{25}$ da IstoÉ sobre o PMM: as fotos em preto e branco buscam a produção de afetos relacionados ao descaso, ao abandono, à desesperança, ao passo que as cores são adotadas a fim de se relacionar com significantes de 'retornar à vida', de esperança, de transformação. A construção positivada sobre o PMM da IstoÉ acontece pela organização de cores e fontes, com apelo à necessidade do profissional de medicina, a fim de mostrar a realidade (pelo menos, a recriada pela revista). 


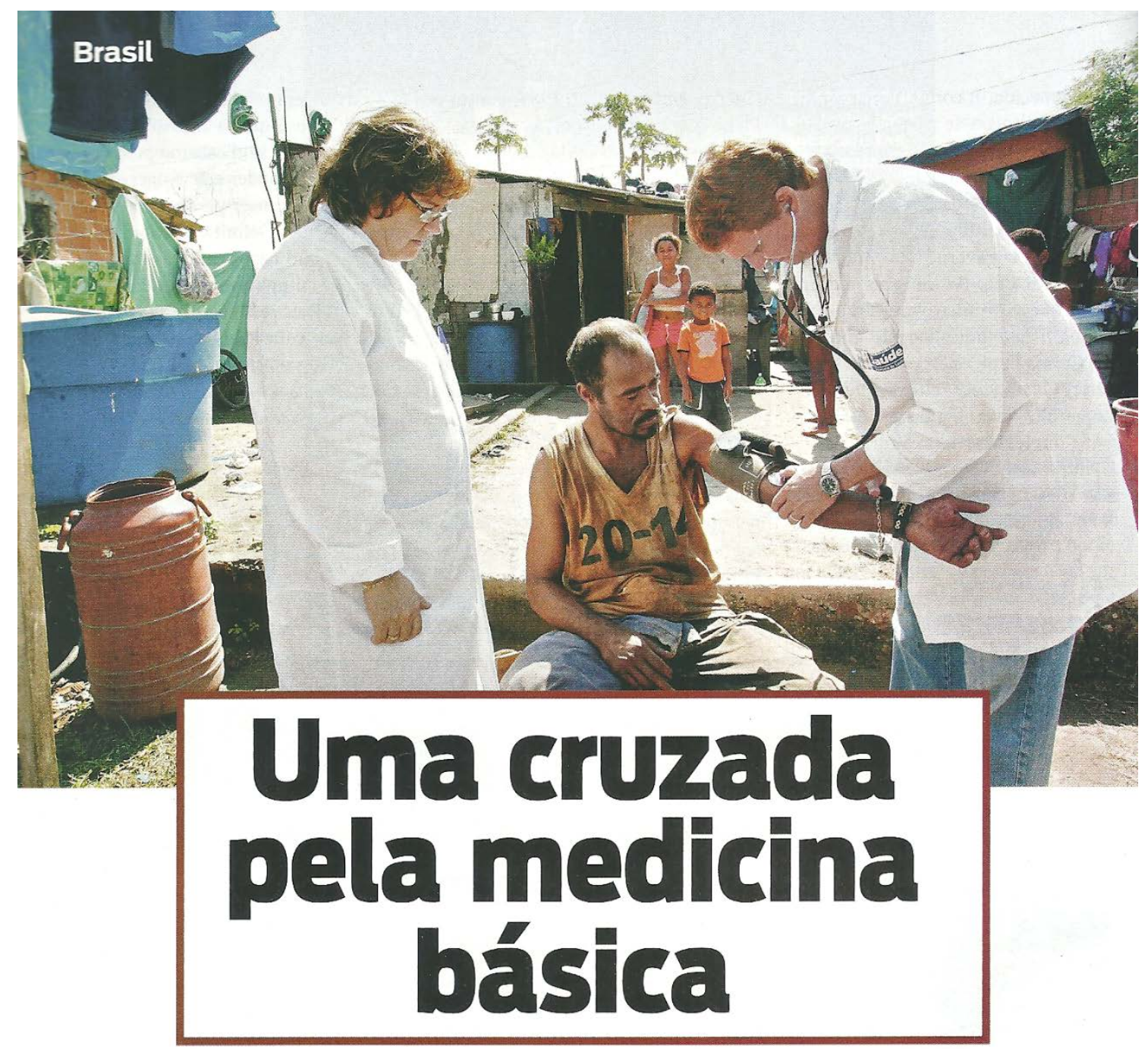

Figura 5. Uma cruzada pela medicina básica

Fonte: Torres (2013) 22 .

\section{Considerações finais}

Considerando que a revista é uma das maiores do país, tendo a classe A como maioria dos seus leitores e que, de maneira geral, a imprensa brasileira critica muito as iniciativas governamentais, sobretudo as que são instituídas por governos de esquerda, surpreende o fato de que a tendenciosidade das notícias seja, em sua maioria, de cunho neutro ou a favor do PMM.

As reportagens veiculadas pela IstoÉ durante o período analisado cumprem um caráter informativo aos leitores, com noções sobre um novo programa de governo e sua polêmica, baseada principalmente na contratação de médicos cubanos. Porém, o embasamento das reportagens, predominantemente, é de informações divulgadas pelo Ministério da Saúde, personagens políticos e entidades médicas. A população atendida pelos profissionais do Programa foi ouvida poucas vezes.

Outro ponto a se considerar é a significância imagética produzida pela IstoÉ sobre o PMM. Enquanto as matérias de 2013 traziam imagens marcantes como a criança negra protegida por um corpo adulto, também negro, ou a cena de um hospital com várias macas no corredor, as produções jornalísticas relativas a 2014 se resumiram a textos mais curtos que os do ano anterior e abordagem mais focada em estratégias eleitorais do que na política pública de saúde. Percebe-se, então, a mudança da utilização do PMM como 
notícia, em que antes era a disputa da corporação médica com o governo e depois é instrumento secundário para argumentação.

Considera-se, portanto, a importância de desconstruir o construído pelos veículos de comunicação no sentido de compreender o que é e quem é relevante em termos midiáticos. Principalmente no campo da saúde, em que populações, histórica e socialmente, foram silenciadas, a comunicação precisa ser instrumento de garantia de direitos humanos. Trazer para dentro e para o centro da notícia suas necessidades em saúde é buscar avançar na prática da equidade e da universalidade do SUS.

\section{Referências}

1. Constituição da República Federativa do Brasil (BR). Seção II, da Saúde [Internet]. Brasília; 1988 [citado em 2017 jan. 15 ]. Redação atualizada em 2015. Disponível em: https://goo.gl/KhPpkZ

2. Presidência da República (BR). Casa Civil. Subchefia de Assuntos Jurídicos. Exposição de Motivos EMI no 00024/2013 MS MEC MP. Projeto de Medida Provisória que institui o Programa Mais Médicos. Brasília; 2013. Anexo da Medida Provisória no 621, de 8 de julho de 2013.

3. Carvalho MS, Sousa MF. Como o Brasil tem enfrentado o tema provimento de médicos? Interface (Botucatu) [Internet]. 2013 dez. [citado em 2015 ago. 2];17(47):913-26. Disponível em: https://goo.gl/RHnaLZ

4. Presidência da República (BR). Casa Civil. Subchefia de Assuntos Jurídicos. Lei no 12.871, de 22 de outubro de 2013. Institui o Programa Mais Médicos para o Brasil, altera as Leis no 8.745, de 9 de dezembro de 1993, e no 6.932, de 7 de julho de 1981, e dá outras providências. DOU [Internet]. 2013 out. 23 [citado em 2016 mar. 4]. Disponível em: https://goo.gl/UfT850

5. Conselho Regional de Medicina (SP). Médicos cubanos: CFM considera a imigração anunciada pelo Ministério da Saúde como medida eleitoreira e irresponsável [Internet]. São Paulo; 2013 [citado em 2015 mar. 14]. Disponível em: http://www.cremesp.org.br/?siteAcao=NoticiasC\&id=2988

6. Atendimento na Atenção Básica melhora com programa de expansão do atendimento médico [Blog do Planalto na Internet]. Portal Brasil; 2014 [citado em 2016 dez. 11]. Disponível em:http://blog.planalto. gov.br/assunto/arthur-chioro/page/6/

7. Comes YTJS, Shimizu HE, Hamann EM, Bargioni F, Ramirez L, Sanchez MN, et al. Avaliação da satisfação dos usuários e da responsividade dos serviços em municípios inscritos no Programa Mais Médicos. Ciênc. Saúde Coletiva [Internet]. 2016 set. [citado em 2017 jan. 03]; 21(9):2749-59. Disponível em: https:// doi.org/10.1590/1413-81232015219.16202016

8. Programa Mais Médicos. Gráfico-resumo de 2016 [Internet]. Brasília; 2016 [citado em 2017 jan. 15]. Disponível em: http://maismedicos.gov.br/resultados-para-o-pais

9. Associação Nacional de Editores de Revista. Circulação. Revistas semanais 2013 x 2014 (Jan-Set) [Internet]. São Paulo; 2014 [citado em 2016 mar. 04]. Disponível em: http://aner.org.br/dados-demercado/circulacao/

10. Minayo MCS. O desafio do conhecimento: pesquisa qualitativa em saúde. 12 ed. São Paulo: Hucitec; 2010.

11. Noto AR, Baptista MC, Faria ST, Nappo SA, Galduróz JCF, Carlini EA. Drogas e saúde na imprensa brasileira: uma análise de artigos publicados em jornais e revistas. Cad. Saúde Pública [Internet]. 2003 fev. [citado em 2016 jun. 15];19(1):69-79. Disponível em http://dx.doi.org/10.1590/S0102$\underline{311 \times 2003000100008}$

12. Teo CRPA. Discursos e a construção do senso comum sobre alimentação a partir de uma revista feminina. Saude Soc. [Internet]. 2010 jun. [citado em 2016 mar. 15];19(2):333-46. Disponível em: https://goo.gl/k718YN

13. Leite PM, Torres I. Por que o Brasil precisa importar médicos. IstoÉ (Editora 3). 2013 jul. 10;2277:38-47.

14. Senado Notícias. Programa Mais Médicos é jogada eleitoreira, diz Cyro Miranda [Internet]. 2013 ago. 06 [citado em 2016 jun. 5]. Disponível em: https://goo.gl/6nhDb9

15. Senado Notícias. José Agripino disse que governo não ouviu o povo [Internet]. 2013 ago. 01 [citado em 2016 jun. 5]. Disponível em: https://goo.gl/y5KZcv 
16. Attuch L. Que venham os cubanos. IstoÉ (Editora 3). 2013 ago. 28;2284:50.

17. Sequeira CD. Entrevista com Alexandre Padilha. IstoÉ (Editora 3). 2013 jun. 5;2272:6-10.

18. Campos E. Mais Médicos não pode ser Mais Marketing. IstoÉ (Editora 3). 2014 mar. 19;2319:42.

19. Costa H. Toma lá, dá cá. IstoÉ (Editora 3). 2013 set. 18;2287:31.

20. Aquino A, Alecrim M. Doentes de ideologia. IstoÉ (Editora 3). 2013set. 04;2285:72-4.

21. Lise que divulga novas vagas para cursos de Medicina. IstoÉ (Editora 3). 2013 dez. 18; 2300:25.

22. Torres I. Uma cruzada pela Medicina Básica. IstoÉ (Editora 3). 2013 jul. 17;2278:40-2.

23. Seixas LF, Francisco EP. Como agenda-setting de atributos e enquadramento podem auxiliar na análise de critérios de noticiabilidade. Anais do 37 Congresso Brasileiro de Ciências da Comunicação; Foz do Iguaçu; 2014 set. 1-5; Foz do Iguaçu-Brasil.

24. Antunes E. Enquadramento: considerações em torno de perspectivas temporais para a notícia. Rev. Galaxia [Internet]. 2009 dez. [citado em 2017 nov. 12];18:85-99. Disponível em: https://revistas.pucsp. br/index.php/galaxia/article/view/2641

25. Moraes SO. O caso Richtoffen na revista Veja. Casa [Internet]. 2008 dez. [citado em 2017 nov. 13];6(2):7. Disponível em: http://seer.fclar.unesp.br/casa/article/view/1201/979 